\begin{tabular}{|c|c|}
\hline & Volume \& Issues Obtainable at The Women University Multan \\
Annals of Social Sciences and Perspective \\
ISSN: 2707-7063, Volume 2, No.1 June 2021
\end{tabular}

\title{
Exploring the Absurdity of War and International Aid in the Novel 'Red Birds' by Mohammad Hanif: A Critical Discourse Analysis
}

\author{
Touqir Nasir'1, Sonia Touqir ${ }^{2}$, Sajid Pervez $^{3}$, Hira Ali ${ }^{4}$
}

\footnotetext{
${ }^{1}$ Sr. Mechanical Engineer, Korea South-East Power Company, Azad Jamu \& Kashmir.

${ }^{2}$ MA English, Bahauddin Zakariya University, Multan, Pakistan.

${ }^{3}$ M.Phil Gender Studies, Bahauddin Zakariya University, Multan, Pakistan.

${ }^{4}$ Lecturer, Department of English, University of Sargodha, Sargodha, Pakistan.
}

\begin{tabular}{lr}
\hline \multicolumn{3}{l}{ ARTICLE DETAILS } \\
\hline History: & \\
Received: & June 01, 2021 \\
Review: & June 27, 2021 \\
Accepted: & June 28, 2021 \\
Available Online: June 30, 2021
\end{tabular}

\section{Keywords:}

Ethical issues, Challenges, Red Birds, International Aid, Polio in Pakistan.

\begin{abstract}
Discourse is a wide-ranging term to cover many forms of human utterances and textual forms of communication. Development through multiple stages gave birth to CDA which bridges the micro-structure of linguistic choices to macro-structures of social reality. Theorists like Van Dijk, Fairclough, and Fowler contributed to its development with the foundation provided by Halliday's SFL. The qualitative research endeavors to analyze 'Red Birds', a novel written by Mohammad Hanif under Huckin's model of CDA to highlight the absurdity of war and international aid. The three dimensions of Fairclough's model are at the background of Huckin's model. The analysis has been carried out at three levels i.e. broad level, sentence level, and word level. A well-thought analysis reveals the nature of war in a region where there is nothing to destroy. It has also been concluded that the aid programs are nothing more than 'making them orphan and then adopting them' which runs incongruous to the spirit of aid.
\end{abstract}

(C) 2021 The Authors, Published by WUM. This is an Open Access article under the Creative Common Attribution Non Commercial 4.0

Corresponding author's email address: soniayaqoob30@ gmail.com

\section{Introduction}

According to Compact Oxford Dictionary (2001), the term 'discourse' refers to written and spoken communication which can be generalized to all walks of life covering a myriad of topics related to the daily activities of human beings speaking a variety of languages across the globe. In semantics and discourse analysis the term refers to some conceptual generalization of conversation. In social practice, discourse also refers to the typical selection of vocabulary or sentence structure which becomes the identity of that particular field such as legal discourse, medical discourse, etc. As per Kiren (2017), in the multi-disciplinary studies 
of language, there is a division among the theorists for the categorization of discourse into text or speech. One of the groups takes speech as discourse and the other group throws its weight in favor of text as discourse. Fairclough (1992) came up with two broad categories i.e. discourse as an abstract noun, discourse as a countable noun. Large units of text and utterances in the form of paragraphs etc. have been placed under the first category while words have been placed under the second category of Fairclough i.e. discourse as countable nouns.

Novels, short stories, and other narrative forms have been placed under the umbrella term discourse by Cook (1992). Hodge and Kress (1988) differentiated among terms like message, text, and discourse. He views message as a comparatively small form of semiotics which is quite specific as far as its content, purpose, and goal are concerned. Whereby text and discourse are larger units with text as the structure of the message and discourse is the social process in which texts are embedded.

\subsection{Discourse Analysis and Critical Discourse Analysis}

It is self-explanatory that discourse analysis is related to the analysis of various aspects of language found in conversation and texts. When more than one user is manipulating the language in a particular context, the given text has multi-dimensional meanings. The study of how language has been shaped with respect to the choice of words e.g. pronouns, articles, adjectives, and other lexical modifications, and the cohesive devices which have been used are analyzed under discourse analysis. At times certain linguists use conversation analysis for the analysis of spoken discourse and text analysis for written discourse.

Critical Discourse Analysis (CDA) is different from traditional discourse analysis because the former provides critical dimensions by exposing certainly hidden or implied meanings of the conversation or the text. In CDA the text is analyzed under a particular context rather than as something which is isolated from social maneuvers. As opined by Scollon (2001), CDA analyses its contents as an indication of social change. In addition, CDA brings to light the construction, deconstruction of certain ideologies of individuals or some group of individuals. The transmission of hidden ideologies and their preservation is also highlighted by CDA. Power relations at the social level are also brought to light by CDA.

\subsection{CDA and Literature}

Van Dijk (1979) views literature as not only a particular corpus of discourses but also a kind of speech act that aims to present social conditions and their effects in the communicative context of writers and their readers. CDA is mostly used for the analysis of media discourses to analyze social trends of power, power abuse in racism, power abuse based on gender inequalities, but literature is also a social product in which multifarious ideologies, different aspects of power, and other social dimensions are embedded. Hence, it is a potential area to be explored through CDA so that the socio-cultural contexts can be highlighted. The novel 'Red Birds' by Mohammad Hanif is also a piece of fictional prose that carries some implicit areas to be explored.

The study aims to highlight the absurd nature of large-scale bombing and destruction caused by American wars in different countries of the Middle East. The colossal bombing is followed by aid programs under different brands to help the victims as well as the survivors of such mechanistic wars of the $21^{\text {st }}$ century. The study is significant and unique in the sense 
that most gender issues are dealt with under CDA, but this research aims to explore the hidden layers of absurd wars and subsequently the aid programs.

\section{Literature Review}

The section has been divided into two sub-headings i.e. the background of the theory and related research works.

\subsection{Background of the Theory}

Taking input from various emerging fields of study, CDA has been passing through different stages of development in which a number of theorists have been adding their dimensions to this broad spectrum theory. Under an umbrella of critical linguistics, different research papers were published at diverse conferences related to the use of language in social institutions to maintain certain cultural norms and values as suited to them and the papers also focused on the relationship between language, ideology, and declaring their works as critical as well as a new angle to linguistic analysis. The persona of Fowler (1979) is also important in this connection. Systemic Functional Linguistic (SFL) by Michael Halliday provided a sound basis to these researchers who were laying the foundation of CDA. Later, CDA also relied on SFL because it provides a complete set of linguistic analyses at clause level which helps to analyze the manipulation done at different levels e.g. lexical, syntactic, etc. to continue the discursive practices in a culture. Taking text as an outcome of discursive practices, critical linguistics aimed to understand the cultural values which establish certain social, economic, and political structures in society. In the sphere of critical linguistics, the entities of linguistic structure lead towards the understanding of macro socio-cultural structures embedded in certain ideologies.

Critical linguistics is in line with Halliday's notion of grammar as a system of choices available to the speaker or listener and the choices are made by the listener or speaker keeping in view the demands of the circumstances or the context of the situation. Afterward, the field was significantly contributed by Van Dijk who studied news reports in the press and the production of racial distinction based on media discourse. The socio-cognitive model of Van Dijk (1993) focuses on the analysis of macro-structures in society. He also asserts that multiple ideologies are there in different structures. Norman Fairclough (2003) also added substantial input to the field of CDA by exposing ideologies and patterns of power in his methodology of analysis. He also relied on the SFL model to dive deeper into the text so that hidden social realities may be brought to light. Thomas Huckin (1997) also added to the development of CDA by describing it as something highly context-dependent. He also discussed that language as a tool of discursive practice is widely used by the centers of power so that they can manipulate social values.

\subsection{Review of Related Research}

Media discourses whether written or spoken are mostly analyzed under the framework of CDA. Speeches delivered by political leaders around the world on different occasions are investigated to explore different angles as per the objectives of different researches. Certain novels have also been analyzed to highlight various dimensions. Some related researches have been viewed briefly.

Kiren \& Awan (2017) with their research entitled Critical Discourse Analysis of Jane Austin's novel Pride and Prejudice analyzed the issue of feminism related to education and 
the status of women in society. This qualitative research used Fairclough's three-dimensional model as a major framework for the intended analysis under CDA. Some points of SFL by Michael Halliday have also been chosen for the analysis of the text. The study concludes that the analysis of the textual chunks reveals that the novelist presents the status of women in that era but she also encourages better standards for women.

Amir \& Mehmood (2017) also explored the ideology working behind Tariq Ali's novel The Stone Women under the title Critical Discourse Analysis of Tariq Ali's Novel 'The Stone Woman': A Corpus Driven Study. Gee's tools have been utilized to explore the ideology behind this novel. Findings suggest that the superiority of male members of the family has become the dominant ideology of society which has been internalized and neutralized by utilizing the institutions of marriage, family along customs and traditions.

Another research with the title Critical Discourse Analysis of Ahmad Ali's Novel Twilight in Delhi by Awan and Yahya (2016) intended to explore the implicit cultural ideologies as well as the relevance of CDA to analyze various dimensions of novel. The paper finds CDA as a useful tool to bring out the cultural differences and their effects on society. The qualitative research also highlights that people living in diverse cultural environments have to face numerous problems that affect not only their personal life but also their social life.

\section{Research Methodology}

Without any trace of numerical data, the research is qualitative to interpret textual chunks to achieve the objectives implicitly given in the title of this research paper i.e. to explore the absurdity of US wars in the $21^{\text {st }}$ century along with relief plans for the displaced. The data has been collected in the form of textual chunks from the novel 'Red Birds' has written by Mohammad Hanif. The selection of the chunks has been made based on purposive sampling for analysis under the broad framework of CDA.

\subsection{Framework of CDA}

The three-tier framework introduced by Fairclough (1989) for the analysis of discourse is a linchpin in CDA and the researches being conducted under this framework. This model is significantly helpful to uncover numerous ideologies embedded in certain texts. The main points of this tri-dimensional model are description, interpretation, and explanation of social reality. The description is the linguistic description of certain features of the text. Interpretation refers to the relationship between the discursive practices and the text where the text is regarded as the ultimate result of all the discursive practices. In the third and final tier of this model, the hidden relationship is explained between discourse and social realities. To put the model in another way, the description is related to what while the interpretation and explanation are related to how and why respectively. In this way, the form of language is used to highlight certain implied meanings of the text.

Thomas Huckin (1997), a professor at the University of Utah, also recorded his contributions by introducing another detailed framework for the analysis of the text of varied magnitude under CDA. The scholars of this discipline not only tend to highlight the social forces behind power abuse but are also inclined to support the victims of oppression. Huckin (1997) provided a set of analytical tools for the analysis under CDA. Generally, most of these tools are an extension of what is called description in the tri-dimensional model of Fairclough but the tools are important distinctively as well because they provide a system to analyze the 
longer texts at different levels i.e. from genre to the level of words. For this purpose, he carries out his analysis at two stages.

In the first stage, he views text from the perspective of an ordinary reader who tries to grasp the overall story of the text with the least involvement of critical angles. In the second stage, he comes up with the steps to analyze the given text from various critical angles from larger text levels to smaller levels i.e. word level. Huckin describes this stage as an interpretation of the text.

\subsubsection{Broad Levels of the Text}

The initial steps of Huckin's framework of CDA deal with the text at the macro level which are described as under. The discussion pertaining to micro and macro levels is also quite relevant following any framework of CDA. The intricate linkage between the two also makes them interdependent. In the sphere of micro-linguistics, smaller units of language systems are related to the formation and modification of lexical items with time. On the other hand, macro-linguistics is related to broader dimensions of language which is the actual concern of CDA which strives to bridge these two aspects to highlight certain ideologies at a larger level, even global may be.

(i) Genre. The text is viewed from a broader perspective to ascertain the category of the text as well as to take into account the writer's choice for a particular paradigm which he/she has chosen.

(ii) Framing. Framing is carried out at different levels during the analysis of the same text. Firstly, the text is framed in a larger context to find out the general direction of some particular text. This stage of framing gives the researcher a clear dimension as to what sort of ideologies he has to look for, keeping in view the first frame of the text. Afterward, subsets of frames are made to dive deep into the text. Certain factors help to understand the frames within the context chosen by the writer. The devices like foregrounding and backgrounding help the researcher to gauge the preferred as well as suppressed dimensions of the text which helps to explore hidden corners of discourse. Another discourse marker, which helps to understand some larger, as well as smaller frames, is presupposition which is frequently used by the writers to achieve certain pragmatic goals.

\subsubsection{Analysis at Sentence Level}

Huckin's setting of framework moves from broader structures to comparatively smaller ones. So, after framing with its supportive devices, there is a sentence-level analysis to analyze certain layers of meanings generated by the writer. The analysis at this level is also accompanied by certain devices which have been briefly mentioned. Topicalization is a technique adopted by the writers to give preference to particular information by providing it the status of the topic sentence. In addition to this, a presupposition is also a useful tool for the analysis at the level of framing as well as at the level of sentences.

\subsubsection{Analysis at Word Level}

The analysis at the level of words and phrases is regarded as a microanalysis of the text. Huckin (1997) has also laid down some guidelines for the analysis of words and phrases in CDA. At this level, connotations can be studied which are used by the writer according to the demand of the context. The broader analysis in the first stage enables the researchers to draw 
meanings from such connotations which themselves carry certain pragmatic values to ascertain the ideologies working covertly in the text. Other indicators, like the use of certain metaphors and particular registers, which indicate the formality or informality of the texts, also contribute towards analysis at the micro-level.

\subsection{The Novel and Its Author at a Glance}

Mohammad Hanif is a graduate of Pakistan Air Force Academy who started his career as a pilot officer but resorted to Journalism after relinquishing his former assignment. His first novel got him enough praise and encouragement in the form of Commonwealth writer's prize to go on with renewed spirit to write 'Red Birds' subsequently. The novel starts with Ellie flying a US warplane who has crash landed in an unknown desert and was rescued by Momo; a teenage boy living in a refugee camp established by USAID and other contributing agencies for the victims and survivors of US war in some countries of Middle East. Momo's father also works for USAID and is mostly observed with a load of files to answer any audit objection in the relief program. This program is at a halt for seven months and he is not being paid but he seems to express loyalty to his employers even at the cost of his family. Momo's mother whose energies are all utilized for her family is always complaining about her husband. Their elder son Ali who started working for the US Army, stationed near the refugee camp, disappeared and the family in general and Momo, in particular, want to bring him back. A sagacious mutt is always accompanied by Momo and several chapters have been dedicated to recording its observations about the happenings in the novel. The story moves with the activities of Momo who has the mind of an entrepreneur intending to turn everything from desert sand to birds into a business empire. The commentary of mutt reveals many happenings of the past related to the family of Momo and this refugee camp. There are other characters like Lady Flowerbody (a funded researcher) and the Doctor who occasionally join the proceedings of the plot. Momo's business-oriented mind plans a deal of exchange Ellie with Ali because he and his family hold the opinion that Ali is in the enforced captivity of the US army stationed in The Hanger (area in possession of the US army). When all of them enter this highly protected area after days of reconnaissance and deliberation they are just encountered with the ghosts of US soldiers along with Ali where the story ends.

\section{Analysis and Discussion}

As the objective of this research is to highlight the absurdity of war and international aid, hence the analysis would also be restricted to selected textual chunks as per the canons of purposive sampling. According to Huckin's model, the analysis at a broader level starts with determining the genre of the literary text and its sub-category, if there is any.

\subsection{Genre}

In a broader sense of the term, the text has been placed under the category of fictional prose with relatively longer in length and several characters that is why the text has been branded as novel and not a short story which is also a type of fictional prose. Cuddon (1976) in his Dictionary of Literary Terms and Literary Theory describes the pre-requisites of a novel as fictional prose which have been described in the previous sentence. Simultaneously, he also describes the sub-categories of the novel as a gothic novel, historical novel and tragic novel, etc. Events taking place in the setting of war, its aftermath, and the occasional aid in which huge sums of money are squandered in futile activities develop a tragic story of the novel where a mother's eyes are always waiting to see her elder son and her ears are anxious to listen to the voice of her firstborn. Momo, the younger son of his mother, also misses the 
company of his elder brother who taught him so many life skills to survive in a desert. But Momo's father thinks that Ali would be able to secure a better future because he has been attached to US soldiers.

The expressions which reflect the setting of war are as under:

There is a war on and what is a war if not an opportunity to make those extra points. Mojor Ellie remembers these words spoken by Colonel Slatter when the former got ejected from his F15 loaded with heavy bombs after the plane developed some technical fault. He was just to hit the camp but could not, he says I can probably go and search for the camp that was in my crosshair for a second, and my thumb was ready to push the drop button. He was in search of the same camp as a refugee which he was going to destroy just a moment ago. He was given the target by Colonel Slatter when he remembers him saying, 'get the goat fuckers but watch for our own. Slatter is indicating him to hit the camp but avoid hitting the place occupied by the US army. According to them, The Hanger is shut. But the refugee camp that's the source of all this trouble still exists. The disappearance of Ali has been remembered by Momo in the words, The day Ali was sold, he was dressed in black overalls but underneath he didn't forget to wear his Boss T-shirt. Of course, Bro Ali had no idea he was being sold. He thought that he was being offered contractual employment at the Hanger. Some are of the view that the father has sold Ali before US soldiers stationed at the Hanger because Momo's father is always on the defensive for US forces and their programs. The woes of the mother after the strange disappearance of her son have been presented in her own words, First, he used to say that Ali is on active duty. I say what about working hours? Weekends? Independence Day Holiday? What kind of job? Why can't he write a letter? Sometimes she curses her self for making the bad decision of sending Ali. She thinks that Momo would have been a better choice in place of Ali because the former is clever and intelligent. The tragic picture of the camp has been given in the words of Major Ellie when he observes, This place reeks of neglect. An outpost in a war that the war itself is not interested in. Nobody is going to come and invade this place. There is nothing to destroy here, nothing to be saved.

All the textual indicators of destruction, gloom and enforced disappearances are sufficient to place this novel under the category of tragic novel teaming with the details of destructing the place which has already been destroyed. Even the refugee camp is in such a state of shambles that it cannot be termed as a camp.

\subsection{Framing}

With the help of pragmatic devices, framing is mainly related to how a particular issue has been presented in a given context and it also takes into account the effects of that issue in the context. It helps to evaluate how the writer is proceeding with a particular perspective in the text. It would be executed under the following headings.

\subsubsection{Foregrounding}

Central points of the narrative discourse are foregrounded by the writers to put more emphasis on certain aspects. Such elements are narrated by different characters so that the core issue may be repeated and asserted. In this heading, the elements related to the objectives of the research will be mentioned and analyzed. The writer has foregrounded the lesser value of human lives in favor of the war in different ways. Mojor Ellie's remarks about the food and other stuff in his flying suit after crash landing are significant in this regard. They give you a 65 million dollar machine to fly, with the smartest bomb, you burn fuel at the 
rate of fifteen gallons per second, and if you get screwed they expect you to survive on four energy biscuits and an organic smoothie. The pilots like Ellie have been given expensive planes to fly which burn fuel in large quantities just in a matter of seconds and the planes are also loaded with high tech bombs but in this scenario, the human life looks to be cheaper even if it is the life of their pilot, just forget for a moment about the lives of those who were going to be the target of these lethal bombs.

Colonel Slatter, whose words have always been echoing in the mind of Ellie after ejection from his F15, takes war as an opportunity to secure points to get high ranks in the service. There is a war on and what is a war if not an opportunity, an opportunity to make up those extra points. The words are hinting towards a war that carries no purpose except making some extra points to get higher ranks. The words of Ellie are important to comprehend a purposeless war in which human beings even their own hold no value at all. He observes, they put GPS chips in pets and migratory birds now, I mean who the hell gets lost these days? And how can someone flying around a 65 million dollar machine get lost? Ellie himself is in a state of shock when he comes across the arrangements made for the recovery and survival of the pilot in such untoward circumstances. Their preference for war even without any substantial reason has been foregrounded quite significantly throughout the novel, Ellie observes 'but the colonel had never resisted a good war or for that matter any war'. Purposeless war has been referred to again in the following words of Ellie, we used to have art for art's sake; now we have a war for the sake of war.

There was a time when art remained the priority for the people and they kept on producing the pieces of art in different forms of art even for no reason but the time has taken a new turn when wars have been pursued merely for the sake of war.

Such wars are followed by a variety of international aid programs in which the representatives of these programs visit these war-stricken areas with entourage and shenanigans and their loaded presence makes things quite opposite to their apparent slogans. In the words of Momo, first, they bomb us from the skies, then they work hard to cure our stress. These words are not only significant to highlight the absurd practices of war and aid, but they also comment on the contradictory states of international players. At another point, Momo describes himself as a laboratory for the research words conducted to describe postwar mental states. Momo says every research scholar who comes this way goes through with their subject. I have been the subject of many studies since I was eleven. Growing Pains in Conflict Zones, Tribal Cultures Get IT. I am a good subject. She is the doctor in the white coat, I am the lab rat quivering in my cage but showing healthy curiosity towards my tormentor. Such studies are going on in the region for many years under one banner or the other and inhabitants of this refugee camp are treated as culture plates of these research works. Lady Flowerbody in the text has been presented as a representative of USAID in the camp who keeps her face well powdered and carries a wide range of beauty products in her possession. Momo's mother also looks fed up with such researchers and their programs when she says, We've had researchers before. They were nice smelling do-gooders who would give us powdered milk and ask about our feelings then note them down in lovely leather-bound notebooks. The writer has presented these aid programs as a kind of lucrative business-like activity that is not aid or help in the real sense of the term. The point has been foregrounded in the words of Momo, She is business-like, making it clear that we are here to discuss my issues, like how I am coping with peace after years of conflict. I am the Young Muslim Mind that will pay for her six-handed massages and her toned skin. For the people living in such war-stricken regions of the world, war and USAID are always followed by each other and 
they take these two activities somewhat synonymous to each other. Mother Dear remarks, the war was coming. And what comes after the war is USAID. The same idea has been foregrounded in the words of mutt whose feelings are also recorded in the novel and several chapters have been allocated to his observations. He also views war and aid through a single lens when he thinks, global security is nothing but social engineering through job creation. First, build a facility, then the man that facility, then hire more people to protect that facility, then hire some dogs to protect those guards, then hire more men to destroy it, then start dreaming up reconstruction contracts. This is a vicious circle of construction and reconstruction, protection and destruction, targeting with bombs and then sending researchers to study the minds how they are feeling after being hit by laser-guided missiles and how they are managing their detrimental losses to their lives of near and dear ones. The absurd practice of gun supplies followed by food supplies has been foregrounded in the words of the Doctor in the camp. The so-called enemy has bigger guns and even bigger food supplies. The Arab residents of different war-stricken countries think that their food supply is strongly linked with falling bombs from the sky.

\subsubsection{Backgrounding and Presupposition}

While embedding the absurdity of war and international aid in the novel, the writer has kept certain things in the background, and it has been assumed that the readers are supposed to comprehend those elements even in the background. The US wars in the Middle East are in the background and with this background in view, the writer has developed this discourse to achieve the desired ends. In the same way, certain terms or nomenclature is also a part of the discourse but additional information, which explains the nature and function of these terms has been kept in the background knowledge. USAID and its representatives have been mentioned time and again, but it has been presupposed that the readers understand all the rest about this agency for aid and development. Things left in the background drive the readers towards the elements foregrounded in the text. Such elements of the text, as given by Huckin's model also play their implied role to build the intended discourse.

\subsubsection{Omission}

The omitted elements are also taken into account as an integral part of CDA according to Huckin's model because the omitted items in the discourse are left omitted intentionally by the writer to convey some meanings covertly in the discourse. In this narrative discourse of the novel, the name or the region where all the happenings are taking place has been omitted by the writer just to give a broad perspective to the discourse of the novel. This omission is an indication that all the wars in that particular region are being pursued under the same purposelessness and the aid programs initiated in all Arab countries are as futile as this one. The camp has not been given any name just to indicate that all the refugee camps and their inhabitants are living in the same miserable conditions. Hence, the omissions are also working to give particular meanings to the discourse covertly.

\subsection{Analysis at Sentence Level}

The gradual approach of Huckin's model for CDA moves from a broader level to the sentence level, and then reaches the level of words to relate the microstructure with the macrostructure of the discourse. The present research, following the same top-down approach, is going to explore the research objectives at the level of sentences. Topicalization is an important device in this regard. 


\subsubsection{Topicalization}

Topicalization conveys the main point in a sentence according to Huckin's model. The research proceeds to analyze the topicalization relevant to the objectives of the research. Topics within the sentences would also be explored to analyze the highlighted topics of different sentences. While living in the camp, Major Ellie observes, Make them orphans, then adopt them, that's how the world goes. The sentence with making them orphans in the topic position reveals the heartlessness of war and the second phrase then adopt them is quite contradictory which reveals that both the practices are futile. They become futile in the context of a basic question that arises from this situation why do you make them orphans if you are going to adopt them. The cosmetic value of the war tribunals has been revealed in the sentence That's just for show.

In another sentence the incongruous states have been described differently, The bigger the guns behind you, the bigger the aid package you attract. The phrase the bigger has been placed in the topic position in both the phrases which complete this sentence in which once again two contrasting concepts have been described complementary which makes them absurd. While observing the dilapidated condition of the refugee camp, Ellie observes, There is nothing to destroy here, nothing to be saved. The sentence under consideration emphasizes nothing in connection with the camp which reveals the fact that it is quite absurd to bomb this place and the residents have nothing to save.

\subsection{Analysis at Word Level}

In its gradual process of exploring a text under CDA, Huckin's model is also concerned with the analysis of words used by the writer to convey some special meanings or ideologies at the macro-level. This analysis can be executed at the following levels.

\subsubsection{Connotations and Metaphors}

The connotation is referred to the meanings of certain words beyond the literal meanings. Though the text under discussion is not rich in such literary devices, there is an occasional use of such words which can also be placed under the research objectives of the present research. Momo whose mind is always overwhelmed by the ideas of business plans to establish an 'Ethical Hunting Project' to hunt the birds of prey and then selling them to Arab Sheikhs in return for hefty sums. In this plan, the term 'Ethical Hunting' has been used under special connotation because hunting cannot be labeled as ethical. The term has been used in the context of US wars which are followed by aid and relief programs to suggest that they have all the ethics in view even in a state of war.

The US researcher in the camp has been named Lady Flowerbody under the connotation of her cosmetic bulk which she carries and the face which she keeps powdered all the time. She is there to study Young Muslim Minds in a post-war conflict and staying at the house of Momo who is like a laboratory for him but at times Momo feels seduced by her pompous looks. Her name has been used by the writer to convey the flamboyant researchers and relief activists who come there clad in spick and span western dresses and their appearances make them look irrelevant in such a mangled refugee camp.

The highly protected area occupied by the American army has always been mention as the Hanger in the text of the novel. The alphabet ' $\mathrm{H}$ ' has always been written in the upper case whenever used in the word hanger just to use it in the connotation of an area, which is ultra- 
special. The signboards with the writing its not thoroughfare and the arrangement of barbed wire over the boundary wall have been used to emphasize the stark difference between the people of two different backgrounds.

There is scant use of metaphors in the discourse in connection with the objectives of the research, but the crashed plane of Major Ellie has been given the name of 'Eagle Strike' which is a use of metaphor. Eagle is a scavenger, but the bomber plane has been called an Eagle. At another point, Ellie calls himself 'a bargaining chip' to be used by the inhabitants of the camp to get food in return.

\subsection{Register}

While discussing the residents of the camp, the writer has used the register of an Arabic Muslim society to spotlight the war against those who are already destroyed in which there is halal food and Momo's mother uses rosary to pronounce the ninety-nine names of Creator on ninety-nine beads of the rosary. Ellie also listens to the call of prayer early in the morning and he observes people going to offer morning prayer.

\section{Findings and Conclusion}

After analyzing the text at different levels according to Huckin's model, the research has reached the following findings keeping in view the objectives as well.

As a global discourse, the text portrays all the wars pursued by the USA have no human value in a view, even their pilot was not rescued and was left on 4 biscuits to survive for eight days in the desert. It was also found that Ellie was going to bomb the place which was already devastated by previous bombings and their consequences. To bomb the place which already presents the scene of destruction is quite meaningless and absurd. To bomb the people who are burdened under the woes of their missing ones and living in this open prison-house would be just like to liberate them from the pangs of life. In this scenario, the war on such people becomes an absurd practice.

The concept of aid and other such programs also becomes meaningless when it is linked with guns and explosives. There has been no bombing in the camp for seven months consequently no aid has been provided during this period. Lady Flowerbody is researching to extend her previous research of Ph.D. thesis without any genuine interest to bring these people out of trauma. When Ellie was coming in his F15 loaded with bombs to hit this camp, what could be the reason behind sending a representative of USAID researcher? Contradictory things going parallel to one another make the whole scenario absurd.

Hence, it is concluded that the novel 'Red Birds' by Mohammad Hanif not only portrays the absurdity of US wars in the $21^{\text {st }}$ century but also exposes the hollowness of international aid and research programs connected with it.

\section{References}

Amir, A., \& Mehmood, A. (2016). Critical Discourse Analysis of Tariq Ali's Novel 'The Stone Woman': A Corpus Driven Study. www.ccsenet.org>ijel>article

Awan, A., \& Yahya, M. (2016). Critical Discourse Analysis of Ahmed Ali's Novel 'Twilight In Delhi'. www.sci-int.com>pdf

Compact Oxford Dictionary. (2001). Oxford: Oxford University Press. 
Cook, G. (1990). Discourse. Oxford: Oxford University Press.

Cuddon, J. (1976). Dictionary of Literary Terms and Literary Theory. $4^{\text {th }}$ ed. New York. Penguin Books.

Dijk, V. (1979). Recalling and Summarizing Complex Discourse. Berlin: de Cruyter. (1993)

Principals of Critical Discourse Analysis. Vol. 4.

Fairclough, N. (1992). Discourse and Social Change. Cambridge: Polity Press (2003). Textual Analysis for Social Research. London: Routledge.

Fowler, R. (1979). Language and Control. London: Routledge.

Hanif, M. (2018). Red Birds. The UK. Bloomsbury Publishers.

Hodge, R. \& Kress, G. (1988). Social Semiotics. Cambridge: Polity Press.

Huckin, T. N. (1997). Critical Discourse Analysis. Retrieved from http://exchange.state.gov/education/engteaching.htm

Kiren, A \& Awan, A. (2017). Critical Discourse Analysis of Jane Austen's Novel 'Pride and Prejudice. www.researchgate.net $>$ publication

Scollon, R. (2001). Mediated Discourse: The Nexus of Practice. London: Routledge. 